\title{
Drying characteristics and quality of lemon slices dried undergone Coulomb force assisted heat pump drying
}

\section{Chin, S. K. ${ }^{\text {a*}}$; Lee, Y. H. ${ }^{\text {; }}$ Chung, B. K. ${ }^{\text {c }}$}

${ }^{a}$ Chemical Engineering, Newcastle University in Singapore, 537 Clementi Road \#6-01, SIT@Ngee Ann Polytechnic Building, Singapore 599493, Singapore

${ }^{b}$ Department of Chemical Engineering, LKC Faculty of Engineering and Science, Universiti Tunku Abdul Rahman, Jalan Sungai Long, Kajang, 43500, Selangor Darul Ehsan, Malaysia

${ }^{\mathrm{c}}$ Department of Electrical and Electronic Engineering, LKC Faculty of Engineering and Science, Universiti Tunku Abdul Rahman, Jalan Sungai Long, Kajang, 43500, Selangor Darul Ehsan, Malaysia

*E-mail of the corresponding author: kent.chin@newcastle.ac.uk

\begin{abstract}
In this research, a Coulomb force assisted heat pump (CF-HP) dryer was invented for the purpose of improving the drying characteristics and product quality of biomaterials. As compared to heat pump drying alone, the assistance of Coulomb force in heat pump dryer enhanced the drying rates and effective moisture diffusivity of lemon slices up to $26 \%$, which eventually shortened the total drying time to $40 \%$. This saved the total energy consumption of HP drying by 31.5\%. High retention of vitamin $C$ and TPC were also found in CF-HP dried slices due to mild drying temperature and fast drying rate.
\end{abstract}

Keywords: Coulomb force; Heat pump drying; Drying rate; Vitamin C; Total Phenolic Content (TPC). 


\section{Introduction}

Heat pump (HP) drying is one of the advanced drying methods that have been used for drying of many agriculture products. It is known as an energy efficient drying method which can produce good product quality as drying is conducted at mild temperature and low relative humidity ${ }^{[1,2]}$. However, mild temperature drying limits the moisture diffusion in the drying materials, which in turn lengthened the total drying time. Hybrid drying involving heat pump combined with other methods such as ultrasound, radio frequency / microwave heating, infrared heating and solar heating also been studied by researchers with the purpose to stimulate the moisture diffusivity and thus drying rate of the drying materials during heat pump drying ${ }^{[3]}$. Nevertheless, most of the hybrid drying methods like are lack of practical application for drying of heat sensitive biomaterials ${ }^{[4]}$.

In this research, an electricity-assisted (Coulomb force) heat pump (CF-HP) drying is proposed as an alternative drying method for the drying of biomaterials such as lemon slices. In CF-HP drying, a high voltage wire mesh is incorporated in the heat pump dryer in order to enhance the removal rate of bound moisture, which in turn counteracts the long drying time required due to mild temperature drying. Owing to the bipolar property of moisture content inside the lemon slices, a positive net force (Coulomb force) can be induced when the lemon slices are placed near to the high voltage, but low frequency mesh. The generated force stimulates the moisture diffusion in the lemon slices which consequently dried by convective air flow produced by heat pump dryer. As there is no heating involved in drying process, the desired properties of the dried lemon slices can be preserved. Hence, CF-HP drying is envisaged to be a successor of heat pump drying in terms of high drying rate and moisture diffusivity, short total drying time, low energy consumption and good quality of dried products.

\section{Materials and Methods}

\subsection{Sample preparation}

Fresh Eureka lemons were sliced crosswise into circular slices. The average thickness of slices was measured as $3.0 \pm 0.5 \times 10^{-3} \mathrm{~m}$ and the initial weight of each slice was recorded as $8.20 \pm 0.05 \times 10^{-3} \mathrm{~kg}$. The average surface area of the slices was calculated as $2.38 \times 10^{-3}$ $\mathrm{m}^{2}$. The lemon slices were dried until equilibrium moisture content (EMC) achieved.

\subsection{Drying methods}

\subsubsection{Heat pump drying}

A laboratory scale heat pump dryer is designed and fabricated by I-Lab Sdn. Bhd., Selangor, Malaysia. The heat pump (HP) dryer consists of a drying chamber of dimensions 
$0.8 \mathrm{~m} \times 0.6 \mathrm{~m} \times 0.6 \mathrm{~m}$ and a heat pump system. Mild temperature dehumidifier air produced by the heat pump system is used as a drying medium and force circulation of convective air is produced by a blower. The dryer was operated at drying temperature of $22^{\circ} \mathrm{C}$ and $34 \%$ relative humidity $(\mathrm{RH})$ when the auxiliary heater was turned off whereas the drying temperature was $31^{\circ} \mathrm{C}$ and $24 \% \mathrm{RH}$ when the auxiliary heater was on. The average air velocity in the chamber was maintained at $1.1 \mathrm{~ms}^{-1}$.

\subsubsection{Coulomb force assisted heat pump drying}

For Coulomb force assisted heat pump (CF-HP) drying, a high voltage system was incorporated inside the heat pump drying chamber, as shown in Fig. 1. The high voltage source which determined to be $1.5 \times 10^{4} \mathrm{~V}$ and $50 \mathrm{~Hz}$, was generated by using a transformer. The output of transformer was connected to the wire mesh, where the string meshes and lemon slices were being loaded on. The effective distance between the lemon slices and wire mesh was determined to be $3 \times 10^{-3} \mathrm{~m}$. The drying condition of the hybrid heat pump drying was similar to heat pump drying in section 2.2.1. CF-HT-HP drying is the CF-HP drying with auxiliary heater being switched on.

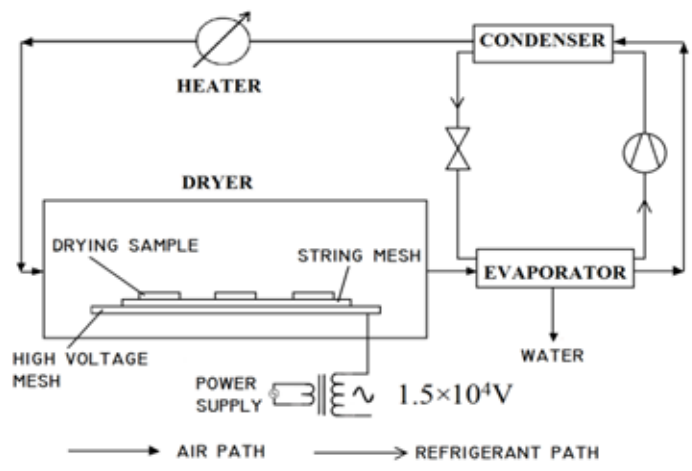

Fig. 1 Simplified diagram of the Coulomb force assisted heat pump (CF-HP) dryer

\subsubsection{Oven drying}

Lemon slices were dried in a laboratory scale hot air convection oven (Memmert, UFB500) at three different temperatures which were $40^{\circ} \mathrm{C}, 50^{\circ} \mathrm{C}$, and $60^{\circ} \mathrm{C}$, at the corresponding relative humidity $(\mathrm{RH})$ of $33.4 \%, 20.2 \%$ and $12.6 \%$, respectively. The average air velocity inside the chamber was determined as $0.6 \mathrm{~ms}^{-1}$. Oven dried lemon slices were used as reference samples which meant for the quality comparison with samples dried by heat pump and Coulomb force assisted heat pump drying methods. 


\subsubsection{Freeze drying}

Lemon slices were pre-frozen in a deep freezer (ARDO-CV382 Upright Freezer) at $-40^{\circ} \mathrm{C}$ for 24 hours, before freeze dried in a laboratory scale freeze dryer (Labconco) at $-40^{\circ} \mathrm{C}$ and 13.3 Pa. The total drying time for freeze drying of lemon slices was set at 48 hours to obtain the optimum vitamin $\mathrm{C}$ and TPC retention in freeze dried lemon slices ${ }^{[5]}$. The freeze dried slices were used as control sample for the determination of vitamin C and TPC in the dried slices subjected to different drying methods.

\subsection{Energy consumption}

Total energy consumption for heat pump and Coulomb force assisted heat pump drying was measured by the power meter (D02A, $\pm 1 \mathrm{~W})$.

\subsection{Drying rate and moisture diffusivity}

The initial moisture content $\left(\mathrm{M}_{0}\right)$, moisture content at a given drying time $t\left(\mathrm{M}_{\mathrm{t}}\right)$, equilibrium moisture content $\left(\mathrm{M}_{\mathrm{eq}}\right)$, moisture ratio $\left(\mathrm{MR}_{\mathrm{t}}\right)$ and drying rate $(\mathrm{R})$ of the lemon slices were calculated by equations $(1)-(5)$ whereas the moisture diffusivity $\left(D_{\text {eff }}\right)$ of the samples was determined using Fick's second model (equation (6)), by assuming the lemon slices to be of the shape of slab.

$$
\begin{aligned}
& M_{0}=\frac{W_{0}-W_{d}}{W_{d}} \quad(1) ; M_{t}=\frac{W_{t}-W_{d}}{W_{d}} \quad(2) ; M_{e q}=\frac{W_{e q}-W_{d}}{W_{d}} \quad \text { (3); } M R_{t}=\frac{M_{t}-M_{e q}}{M_{0}-M_{e q}} \\
& R=\frac{W_{d}}{A_{s}}\left|\frac{F_{t+1}-F_{t}}{t_{i+1}-t_{i}}\right| \quad(5) ; \quad M R=\frac{8}{\pi^{2}}\left[\sum_{n=0}^{99} \frac{1}{(2 n+1)^{2}} \exp \left(\frac{-(2 n+1)^{2} \pi^{2} D_{e f f} t}{l^{2}}\right)\right]
\end{aligned}
$$

Where $W_{0}, W_{t}, W_{d}$, and $W_{e q}$, refer to initial weight of the sample (kg), weight of the sample in the middle of drying process at time $t(\mathrm{~kg})$, bone dry weight of the sample $(\mathrm{kg})$, and equilibrium weight of the sample $(\mathrm{kg})$, respectively. $A_{s}$ is denoted as the surface area of the samples $\left(\mathrm{m}^{2}\right), F_{t}$ is the free moisture content of the sample at time $t\left(\mathrm{~kg} \mathrm{H}_{2} \mathrm{O} / \mathrm{kg}\right.$ dry material). $1, \mathrm{t}$ and $\mathrm{n}$ are the sample's thickness (m), drying time (s) and a positive integer, respectively.

\subsection{Quality analysis}

\subsubsection{Vitamin $C$}

Dried lemon slices were cut into small pieces of equivalent size and subjected to extraction process at $4^{\circ} \mathrm{C}$ for 24 hours using $0.05 \mathrm{~L}$ of metaphosphoric acid-acetic acid (HPO3$\mathrm{CH} 3 \mathrm{COOH}$ ) as extracting solvent. After removal of solid slices by vacuum filtration, the supernatants were titrated into $5 \times 10^{-3} \mathrm{~L}$ of indophenol standard solution (IS). The amount 
of supernatants, Vs used to decolourize the IS solution was recorded. Equation (7) was used to determine the vitamin C (kg Ascorbic acid / kg dry weight) in dried lemon slices which derived based on the standard curve obtained using Ascorbic Acid as standard solution ${ }^{[6]}$.

$$
\text { Vitamin } C=\frac{0.31 V}{V_{s} W_{d}}
$$

Where $\mathrm{V}$ is the volume of the extracting solution used (L)

\subsubsection{Total phenolic content (TPC)}

Similar to vitamin $\mathrm{C}$ analysis, dried lemon slices were cut into small pieces of equivalent size and subjected to extraction process at $4^{\circ} \mathrm{C}$ for 24 hours using $0.05 \mathrm{~L}$ of solvent which made up of acetone, distilled water and hydrochloric acid in volume percentage of $75 \%$, $22 \%$ and $3 \%$, respectively. After removal of solid slices by vacuum filtration, $1 \times 10^{-3} \mathrm{~L}$ of supernatant was titrated into $5 \times 10^{-3} \mathrm{~L}$ of $0.2 \mathrm{~N}$ Folin-Ciocalteau reagent and held for 3 minutes. Then, $4 \times 10^{-3} \mathrm{~L}$ of $7.5 \%$ sodium carbonate solution (Na2CO3) was added into the mixture and incubated in dark at room temperature for 30 minutes to allow colour development. Subsequently, the extract was adjusted with $0.04 \mathrm{~L}$ of distilled water and the absorbance (A) of the extract was measured at $7.65 \times 10^{-7} \mathrm{~m}$ in a single beam spectrophotometer (JENWAY 6320D). Equation (8) was used to determine the TPC (kg Gallic acid / kg dry weight) in dried lemon slices which derived based on the standard curve obtained using Gallic acid as standard solution ${ }^{[7]}$.

$$
\mathrm{TPC}=\frac{A D_{f} V}{9.02 W_{d}}
$$

Where $\mathrm{D}_{\mathrm{f}}$ is dilution factor.

\section{Results and Discussion}

\subsection{Drying rate, effective moisture diffusivity and total drying time}

Table 1. Average drying rate, effective moisture diffusivity and total drying time of heat pump and Coulomb force assisted heat pump dried lemon slices

\begin{tabular}{|c|c|c|c|}
\hline Drying Method & $\begin{array}{c}\text { Rate (R) } \\
\left(\times 10^{-5} \mathrm{~kg} \mathrm{H}_{2} \mathrm{O} /\right. \\
\left.\mathrm{m}^{2} . \mathrm{s}\right)\end{array}$ & $\begin{array}{c}\text { Effective } \\
\left.\text { Diffusivity (D }{ }_{\text {eff }}\right) \\
\left(\times 10^{-11} \mathbf{m}^{2} \mathbf{s}^{-1}\right)\end{array}$ & $\begin{array}{l}\text { Reduction of Total } \\
\text { Drying Time (\%) }\end{array}$ \\
\hline $\mathrm{HP}$ & 5.33 & 2.95 & - \\
\hline CF-HP & 5.83 & 3.25 & 31.6 \\
\hline CF-HT-HP & 6.67 & 3.73 & 39.9 \\
\hline
\end{tabular}

\section{Average Drying Average}


Table 2. Power and total energy consumption of heat pump and Coulomb force assisted heat pump drying methods

\begin{tabular}{ccc}
\hline Drying Method & Power $(\mathbf{W})$ & Total Energy Consumption $\left(\times \mathbf{1 0}^{\mathbf{8}} \mathbf{J}\right)$ \\
\hline HP & 1723.07 & 9.20 \\
CF-HP & 1726.62 & 6.30 \\
CF-HT-HP & 3150.11 & 10.11 \\
\hline
\end{tabular}

As shown in Table 1, the highest average drying rate was found for CF-HT-HP drying, followed by CF-HP and HP drying of lemon slices. As compare to heat pump drying alone, the average drying rate and effective moisture diffusivity of Coulomb force assisted heat pump drying were found to improved up to $25.1 \%$ and $26.4 \%$, respectively. The induced Coulomb force in lemon slices during hybrid heat pump drying decreased external mass transfer resistance rendered by the high electric field, which consequently intensified the drying rate and enhanced the moisture diffusivity from core to product surface. This reduced the total drying time of $31.6 \%$ and $39.9 \%$ for CF-HP and CF-HT-HP drying, respectively. In terms of energy consumption, CF-HP drying is more efficient in energy saving as it required the least energy, which is only $68.5 \%$ and $62.3 \%$ of the total amount of energy required by HP and CF-HT-HP drying, respectively as indicated in Table 2.

\subsection{Vitamin C content of dried lemon slices}

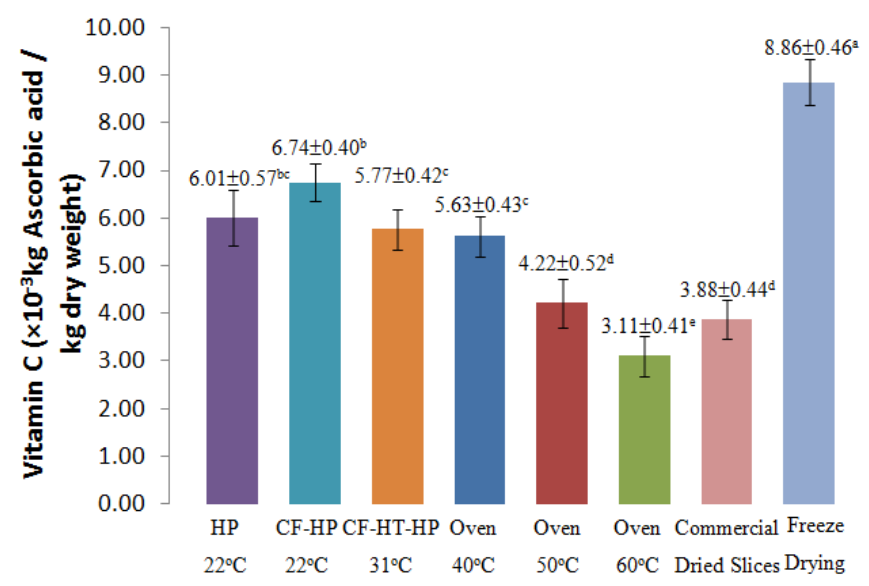

Fig. 2. Comparison of vitamin $C$ in lemon slices for different drying methods. Vitamin $C$ contents with different superscript letters indicate a significant difference at $p<0.05$.

Based on Fig. 2, except for freeze dried samples, CF-HP dried lemon slices showed the highest amount of vitamin $\mathrm{C}$ among all samples. The vitamin $\mathrm{C}$ content of CF-HP dried slices is significantly higher than oven dried slices due to mild temperature drying condition 
and high drying rate. Similar to this, the amount of vitamin C in heat pump and CF-HT-HP dried samples were found to be $2.5 \%$ to $93.2 \%$ higher than oven dried samples. This indicates drying of lemon slices at mild temperature could minimize the deterioration of vitamin $\mathrm{C}$ during the dying process. In addition, integration of Coulomb force in heat pump drying (CF-HP) enhanced the drying rate and shortened the total drying time required as compared to HP drying which led to a better vitamin $\mathrm{C}$ retention in dried lemon slices. Due to increased drying temperature, the used of auxiliary heater in CF-HT-HP drying reduced the vitamin $\mathrm{C}$ content in lemon slices as compared to those dried with CF-HP and HP method, resulted in lower vitamin $\mathrm{C}$ content similar with those found in lemon slices dried at $40^{\circ} \mathrm{C}$. Lowest amount of vitamin $\mathrm{C}$ in $50^{\circ} \mathrm{C}$ and $60^{\circ} \mathrm{C}$ oven dried lemon slices could be due to combination of thermal and oxidative degradations of vitamin $\mathrm{C}$. However, freeze dried lemon slices preserved the highest vitamin $\mathrm{C}$ among of all as drying at high vacuum could mitigate oxidative degradation of vitamin $C^{[6]}$. Commercial dried products which commonly dried by solar or hot air drying method are found to retain low amount of vitamin $\mathrm{C}$ attributed to thermal degradation and oxidative destruction of vitamin $\mathrm{C}$ due to prolong drying time ${ }^{[7]}$.

\subsection{TPC content of dried lemon slices}

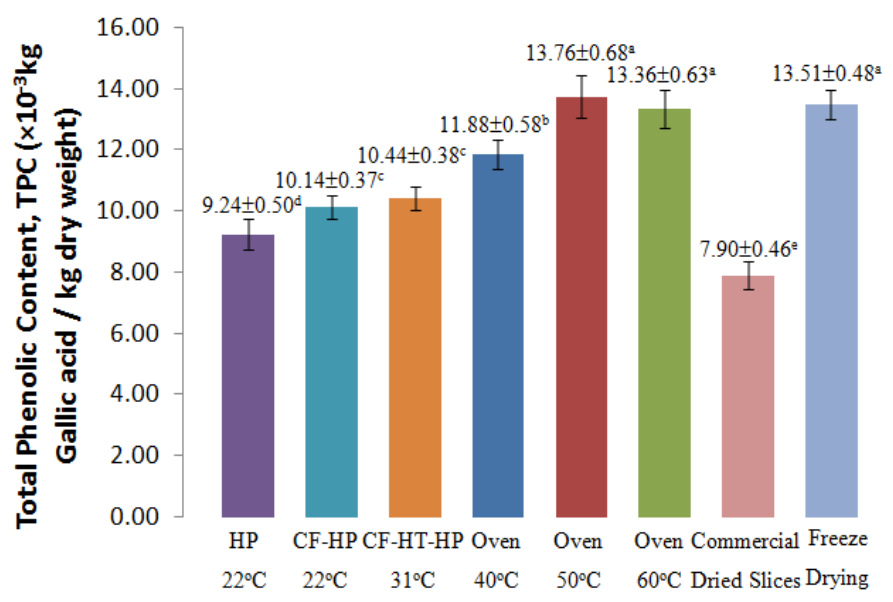

Fig. 3. Comparison of total phenolics content (TPC) in lemon slices for different drying methods. TPC with different superscript letters indicate a significant difference at $p<0.05$.

In contrast to the retention of vitamin $\mathrm{C}$, oven dried slices at elevated temperature $\left(50^{\circ} \mathrm{C}\right.$ and $60^{\circ} \mathrm{C}$ ) retained the highest amount of TPC as shown in Fig 3. According to VegaGalvez et al., high retention of TPC in fruits dried at elevated temperature could be due to the conversion of phenolic molecules from other forms of phenolic compounds, which led to greater amount detected ${ }^{[8]}$. Furthermore, high drying rate and short drying time of the 
lemon slices at elevated temperature also prevents the degradation of TPC attributed to volatilization, oxidation and heat destruction process. The effect of drying rate and drying time on the TPC of dried slices was further shown by the heat pump and hybrid heat pump dried slices. Among of them, the TPC in CF-HP and CF-HT-HP dried slices were insignificantly different, but they were significantly higher than the TPC of HP dried slices although drying was conducted at mild temperature. Similar to the results of vitamin $\mathrm{C}$ analysis, TPC in commercial dried lemon slices was the lowest among of all due to low drying rate and prolong drying time of open sun drying or solar drying.

\section{Conclusion}

Coulomb force assisted heat pump drying intensified the drying rates, enhanced the moisture diffusivity and consequently reduced the total energy consumption and drying time of lemon slices as compared to conventional heat pump drying method. In terms of product quality, it appears that CF-HP drying is a highly recommended drying method for the preservation of antioxidants.

\section{References}

[1] Chua, K.J.; Chou, S.K.; Yang, W.M. Advances in heat pump systems: a review. Applied Energy 2010, 87(12), pp. 3611 - 3624.

[2] Goh, L.J.; Yusof Othman, M.; Mat, S.; Ruslan, H.; Sopian, K. Review of heat pump systems for drying application. Renewable and Sustainable Energy Reviews 2011, 15(9), pp. 4788 - 4796.

[3] Patel, K.K.; Kar, A. Heat pump assisted drying of agricultural produce an overview. Journal of Food Science and Technology 2012, 49(2), pp. 142 - 160.

[4] Barzegar, M.; Zare, D.; Stroshine, R.L. An integrated energy and quality approach to optimization of green peas drying in a hot air infrared-assisted vibratory bed dryer. Journal of Food Engineering 2015, 166, pp. 302 - 315.

[5] Lai, M.W. Vitamin C Retention of freeze dried lemon fruit slices under different freeze drying conditions. Universiti Tunku Abdul Rahman. Kuala Lumpur, 2014.

[6] Burg, P.; Fraile, P. Vitamin C destruction during the cooking of a potato dish. LWT Food Science and Technology 1995, 28(5), pp. 506 - 514.

[7] Ndawula, J.; Kabasa, J.; Byaruhanga, Y. Alterations in fruit and vegetable $\beta$-carotene and vitamin $\mathrm{C}$ content caused by open-sun drying, visqueen-covered and polyethylenecovered solar-dryers. African Health Sciences 2004, 4(2), pp. 125 - 130.

[8] Vega-Gálvez, A.; Scala, K.D.; Rodriguez, K.; Lemus-Mondaca, R.; Miranda, R.; Lopez, J.; Perez-Won, M. Effect of air drying temperature on physico-chemical properties, antioxidant capacity, color and total phenolics content of red pepper. Journal of Food Chemistry 2009, 117(4), pp. 647 - 653. 